\title{
Evaluating the effect of ultrasound-guided superficial serratus plane block, deep serratus plane block and thoracic epidural analgesia in cancer patients undergoing thoracotomy: A randomized controlled trial
}

\author{
Ayman Sharawy Abdelrahman ${ }^{1} \bowtie$, Mohamed Mosaad AI Wasseef ${ }^{2} \bowtie$, \\ Mohamed Elsayed Hassan ${ }^{3} \square$, Ekramy M Abdelghafar ${ }^{3} \square$
}

Author affiliations:

1. Assistant Lecturer of Anesthesia and Pain Medicine, National Cancer Institute, Cairo University, Cairo, Egypt.

2. Professor of Anesthesia and Pain Medicine, National Cancer Institute, Cairo University, Cairo, Egypt.

3. Assistant Professor of Anesthesia and Pain Medicine, National Cancer Institute, Cairo University, Cairo, Egypt

Correspondence: Dr. Ayman Sharawy Abdelrahman; ORCID ID: https://orcid.org/0000-0002-1109-9523; Address: $4^{\text {th }}$ El Nozha st. - El Maadi-Cairo, Egypt; Email: ayman.sharawy@nci.cu.edu.eg; Telephone: 00201282649008

\section{Abstract}

Background \& objective: The serratus anterior plane block (SAPB) is a recent technique providing effective perioperative analgesia in thoracic surgeries. This study compared the intra-operative hemodynamics and the perioperative analgesic efficacy of superficial SAPB, to deep SAPB, and to thoracic epidural analgesia in thoracotomies.

Methodology: one hundred and eighty lung cancer patients scheduled for thoracotomy were randomly allocated to three groups; TEA group, which received thoracic epidural analgesia, SSPB group receiving ultrasound-guided superficial serratus plane block and DSPB group which received US-guided deep serratus plane block. Baseline and intra-operative hemodynamics and total consumption of intraoperative fentanyl and postoperative morphine was noted.

Results: Intra-operative mean arterial pressure (MAP) significantly decreased in the TEA group compared to baseline values, whereas no significant changes were found in either SSPB or DSPB groups. Heart rate (HR) did not show significant changes in any group. The time to postoperative analgesic demand was significantly longer in the SSPB and DSPB groups than in the TEA group $(p<0.001)$. In the first postoperative hour, TEA group had significantly higher visual analogue scale (VAS) scores than SSPB or DSPB groups at rest and with cough. The total consumption of intraoperative fentanyl and postoperative morphine was comparable among all groups.

Conclusion: Pre-operative SSPB and DSPB can provide adequate perioperative analgesia without hemodynamic instability when compared to TEA in thoracotomies.

Key words: Deep serratus plane block; Superficial serratus plane block; Thoracic epidural analgesia; Analgesia; Thoracotomy

Trial registration: The trial was registered at ClinicalTrials.gov with registration number (NCT 04189120). https://clinicaltrials.gov/ct2/show/NCT04189120

Citation: Abdelrahman AS, AI Wasseef MM, Hassan ME, Abdelghafar EM. Evaluating the effect of ultrasound-guided superficial serratus plane block, deep serratus plane block and thoracic epidural analgesia in cancer patients undergoing thoracotomy: A randomized controlled trial. Anaesth. pain intensive care 2021;25(6):713-721; DOI: 10.35975/apic.v25i6.1690 


\section{Introduction}

Thoracic surgery is known to cause considerable postoperative pain. The pain can be caused by surgical incision, rib retraction, costovertebral joint dislocation, intercostal nerves damage, insertion of chest tube at the end of the surgery, or stretching of the brachial plexus and shoulder muscles of the ipsilateral side. ${ }^{1}$

Acute post-thoracotomy pain (PTP) can intervene vigorous physiotherapy and spirometer usage, which are essential to prevent atelectasis and retention of secretions. Therefore, adequate pain control is essential to facilitate coughing, deep breathing and allow early mobilization. $^{2}$.

The variety of pain sources in thoracotomy necessitates a multimodal analgesic technique to address the different pain locations. Thoracic epidural analgesia (TEA), paravertebral block (PVB), and intercostal nerve block are among the regional anesthetic techniques used in combination with systemic analgesic medications. ${ }^{3}$

The gold standard for PTP management is TEA. ${ }^{4}$ However, TEA carries the risk of complications such as hemodynamic instability, epidural hematoma or abscess, in addition to neuraxial opioid side effects, such as nausea and vomiting, urine retention, pruritus, and respiratory depression. ${ }^{5}$

The serratus anterior plane block (SAPB) is a potentially novel regional anesthetic technique that has been effective in treating PTP. Its analgesic effect is thought to be via blocking lateral cutaneous branches of the intercostal nerves. It avoids autonomic blockade and serious complications including injury of the pleura and central neuraxial structures. Furthermore, SAPB can be done under ultrasound (US)-guidance which facilitates the block and guarantees proper injection of the local anesthetics in plane either superficial or deep to the serratus muscle. ${ }^{6}$

This study was conducted to compare the intra-operative hemodynamics and the perioperative analgesic efficacy of superficial SAPB, to deep SAPB, and to thoracic epidural analgesia in thoracotomies.

\section{Methodology}

This prospective randomized controlled study involved 180 lung cancer patients aging from 18 to 60 years and classified according to the American Society of Anesthesiologists (ASA); class II. The patients were scheduled for thoracic surgeries (metastasectomy or lobectomy). The study was registered in ClinicalTrials.gov (NCT04189120) and approved by the local Ethical Committee of the Anesthesia Department. Informed written consent was obtained from patients before enrollment in the study. The study was done at National Cancer Institute, Cairo University, from April 2019 to May 2021. Patients with cognitive problems, coagulopathy, or local infection at the puncture site were excluded from the study.

\subsection{Randomization:}

Participants were randomly assigned in a parallel manner to one of three equal groups (each of 60 patients), where a group received thoracic epidural analgesia (TEA group), another one received US-guided superficial serratus plane block (SSPB group), lastly a group received US-guided deep serratus plane block (DSPB group). A computer-generated list was kept in a sealed envelope for randomization.

\subsection{Preparation:}

Routine preoperative assessment was done to all patients. The study protocol was explained to the patients and their consents were taken. All patients were made familiar with the use of the visual analog scale (VAS), where 0 score represented no pain and 10 represented the worst imaginable pain. The pulse, blood pressure, and oxygen saturation were continuously monitored in the holding room. An intravenous (IV) 18-gauge cannula was inserted for all patients. IV Midazolam $0.02 \mathrm{mg} / \mathrm{Kg}$ was administered. Portable ultrasound machine, resuscitation equipment and drugs (e.g. epinephrine, lipid emulsion), sterile gloves and surgical towels were present.

\subsection{TEA group:}

Skin infiltration with $2 \mathrm{ml}$ of $1 \%$ lidocaine was performed under full aseptic conditions while the patient was in the sitting position. Then, an 18-G Tuohy needle with a $20-\mathrm{G}$ catheter (Perifix ${ }^{\circledR}, \mathrm{B}$. Braun, Germany) was inserted through the T6-T7 interspace, and the epidural space was located using the loss of resistance approach. To identify inadvertent intrathecal or IV injection, a test dose of $3 \mathrm{ml}$ of $1 \%$ lidocaine with epinephrine in a ratio of 1:200,000 was injected. After a negative reaction, the patient was given $10 \mathrm{~mL}$ of $0.25 \%$ epidural bupivacaine and rested into the supine position.

\subsection{Superficial SAPB and deep SAPB groups:}

A portable ultrasound machine $(\mathrm{M}-$ turbo®; FUJIFILM Sonosite Inc., Bothell, WA, USA) was used. A sterile area was prepared using a povidone iodine solution while the patient was in a lateral posture with the diseased side up. Over the fifth rib in the mid-axillary line, a linear ultrasound transducer (10-12 MHz) was positioned, covered with a disposable sterile cover. The latissimus dorsi (superficial and posterior), teres major (superior), and serratus muscles (deep and inferior) were identified as muscles that overlie the fifth rib. A $1 \%$ lidocaine skin 

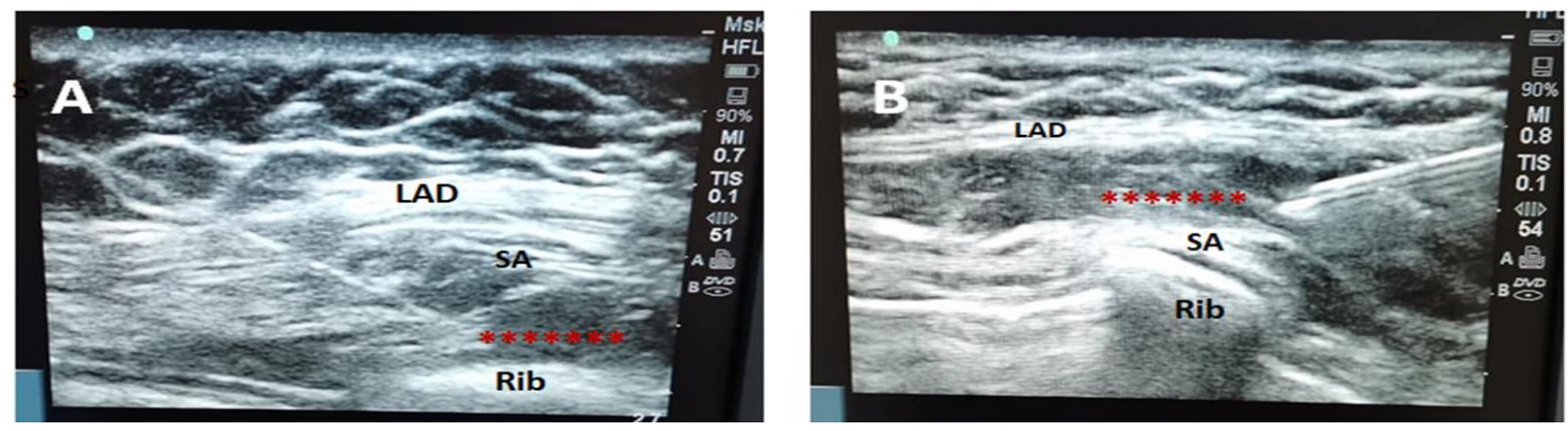

Figure 1: A: DSPB and B: SSPB, LAD: Latissimus Dorsi, SA: Serratus Anterior muscle, red stars denote local anesthetic spread.

wheal was formed $1 \mathrm{~cm}$ from the lateral border of the transducer, through which the needle $(22-\mathrm{G}, 50-\mathrm{mm}$ Stimuplex ${ }^{\circledR}$ A; B Braun, Melsung, Germany) was introduced. The ultrasound probe was placed targeting the plane deep to the serratus muscle separating the serratus anterior muscle and the fifth rib in the DSPB group (Figure 1A), or superficial to the serratus muscle underneath the latissimus dorsi in the SSPB group (Figure 1B). Then, $30 \mathrm{ml}$ of $0.25 \%$ bupivacaine was injected under ultrasound guidance to ensure the exact injection location.

After each block the sensory level was evaluated by the loss of pinprick sensation approach along the anterior axillary line targeting T2- T10 dermatomal block for 20 min after the block was completed. Lack of evident loss of pinprick sensations in the targeted dermatomes indicated an unsuccessful block. Patients with failed blocks were excluded from the study.

\subsection{Intra-operative:}

All patients of successful blocks received fentanyl 100 $\mu \mathrm{g}$ IV, propofol $2-3 \mathrm{mg} / \mathrm{kg}$ and rocuronium $0.5-0.8$ $\mathrm{mg} / \mathrm{kg}$ to conduct general anesthesia. Isoflurane (1-2\%) in $50 \%$ air in oxygen mixture was used to maintain anesthesia. After that, all patients were intubated by double lumen left endobronchial tube and mechanically ventilated by volume controlled positive pressure ventilation. To maintain end tidal carbon dioxide tension around $35 \mathrm{mmHg}$, tidal volume of $6-8 \mathrm{~mL} / \mathrm{kg}$ and $\mathrm{I} / \mathrm{E}$ ratio 1:2 were used. All patients were monitored with 5 leads electrocardiogram (ECG), non-invasive blood pressure monitoring (NIBP), pulse oximetry and endtidal $\mathrm{CO}_{2}$. After ensuring the proper position of the double lumen tube, the patients were positioned in the lateral position with the diseased side up.

Mean arterial blood pressure (MAP) and heart rate (HR) were recorded after injection of the local anesthetics then every $5 \mathrm{~min}$ for the first $15 \mathrm{~min}$ lastly every $15 \mathrm{~min}$ till the end of the surgery. Hypotension (MAP $<65 \mathrm{mmHg}$ ) was treated with IV ephedrine, 5-to-25 mg, while elevation of $\mathrm{HR}$ and/or MAP $\geq 20 \%$ of the baseline were treated by fentanyl $0.5 \mu \mathrm{g} / \mathrm{kg}$. The total amount of intraoperative fentanyl used for every patient was recorded.

All patients in this study underwent the same surgical technique; posterolateral thoracotomy with sparing the serratus anterior and trapezius muscles, and the surgical closure technique was periosteal suturing with intercostal nerve protection.

\subsection{Postoperative:}

After the surgery, the patients were replaced on supine position and after extubation of fully conscious patients; they were then transferred to the ICU where a multimodal approach for postoperative pain control was adopted in the form of acetaminophen, $1 \mathrm{~g}$ every 8 hours, (Injectemol@, Pharco B International). IV morphine (4 $\mathrm{mg}$ ) was provided as a rescue analgesia when VAS score $\geq 4$, followed by continuous infusion of morphine by patient-controlled analgesia (PCA) device (Accufuser Plus® REF M5015L) -that was prepared by $60 \mathrm{mg}$ morphine, $90 \mathrm{mg}$ ketorolac and $3 \mathrm{mg}$ granisetron over total volume of $300 \mathrm{ml}$ normal saline with basal infusion rate $5 \mathrm{ml} / \mathrm{h}$ and $1 \mathrm{ml}$ bolus followed by $15 \mathrm{~min}$ lockout to keep the VAS scores $<4$.

\subsection{Sample size calculation:}

The sample size was calculated using $\mathrm{G}^{*}$ Power 3.1.9.2 (Universitat Kiel, Germany). We performed a pilot study (10 cases in each group) and we found that the mean intraoperative MAP (the primary outcome) was 81.75 $\mathrm{mmHg}$ in TEA group, $87.29 \mathrm{mmHg}$ in SSPB group and $86.77 \mathrm{mmHg}$ in DSPB group (SD \pm 8.77). The following factors were taken into consideration during sample size calculations: 0.28 effect size, 95\% confidence limit, group ratio 1:1 and 5 cases were added to each group to overcome dropout and $90 \%$ power of the study. Therefore, 60 patients were recruited in each group.

\subsection{Statistical analysis:}




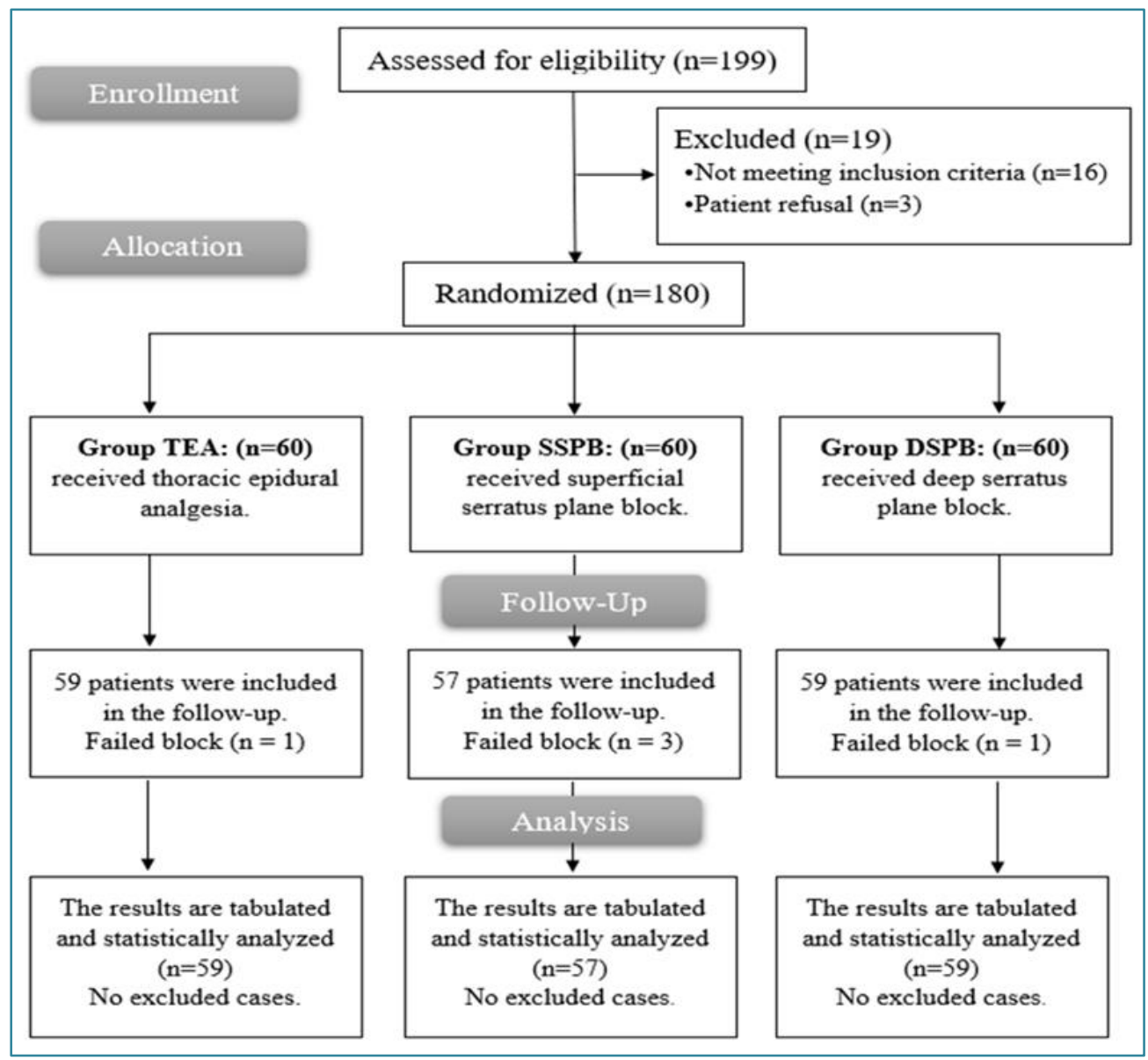

Figure 2: CONSORT flow diagram

Data analysis was done using the SPSS v25 (IBM Inc., Chicago, IL, USA). To assess the distribution of quantitative variables, the Shapiro-Wilks normality test and histograms were employed to identify the appropriate form of statistical testing: nonparametric versus parametric. Quantitative parametric data were reported as mean and standard deviation (SD) and compared between the three groups using the F test, with a post hoc (Tuckey) test to compare each two groups. Quantitative non-parametric variables were analyzed using Kruskal-Wallis test and were expressed as median and interquartile range (IQR) and; Mann-Whitney (U) test was performed for further analysis to compare each two groups. Categorical variables were statistically analyzed by Chi-square test and reported as frequency and percentage. A two tailed $\mathrm{p}$-value $\leq 0.05$ was considered statistically significant.

\section{Results}

In this study, 199 patients were checked for eligibility, 19 patients were excluded. The remaining 180 patients were allocated randomly to one of three groups (60 patients in each one). Failed block occurred in one patient in TEA group, 3 patients in SSPB group, one patient in DSPB group and only the remaining patients were followed-up and analyzed statistically (Figure 2).

The three groups were comparable regarding age, sex, duration of anesthesia and duration of surgery. Procedure time was significantly shorter in SSPB group and DSPB group compared to TEA group and was significantly shorter in DSPB group than SSPB group ( $\mathrm{p}<$ 0.001) (Table 1).

The MAP was significantly lower in TEA group at 5,10 , 15,30 and $45 \mathrm{~min}$ after injection of the local anesthetics compared to the SSPB group $(p<0.001$ from 5 to 30 min and $p=0.012$ at $45 \mathrm{~min}$ ) and DSPB group ( $<0.001$ from 5 to and $\mathrm{p}=$ 0.001 at $45 \mathrm{~min})$ while there were insignificant differences between SSPB and DSPB groups at all-time points after local anesthetic injection (Figure 3). The HR was comparable among the three groups during the intraoperative period. (Figure 4).

The total intra-operative fentanyl consumption showed no significant differences between TEA (134.41 \pm 32.66 $\mu \mathrm{g})$, SSPB $(135.79 \pm 33.16 \mu \mathrm{g})$ and DSPB $(134.58 \pm$ $35.15 \mu \mathrm{g})$ groups $(\mathrm{p}=0.771)$.

VAS score at rest and at cough was comparable among the three groups at all-time points except at ICU admission and at 1 hour from admission to ICU where VAS score was significantly lower in SSPB and DSPB groups compared to TEA group, whereas both SAPB groups showed comparable values (Table 2, Table 3).

TEA Group: thoracic epidural analgesia group, SSPB group: superficial serratus plane block group, DSPB Group: deep serratus plane block group, IQR: inter quartile range. *significant as $\mathrm{p}$-value $<0.05, \mathrm{P} 1$ : $\mathrm{P}$ value between group TEA and group SSPB, P2: p-value

\section{6 www.apicareonline.com}




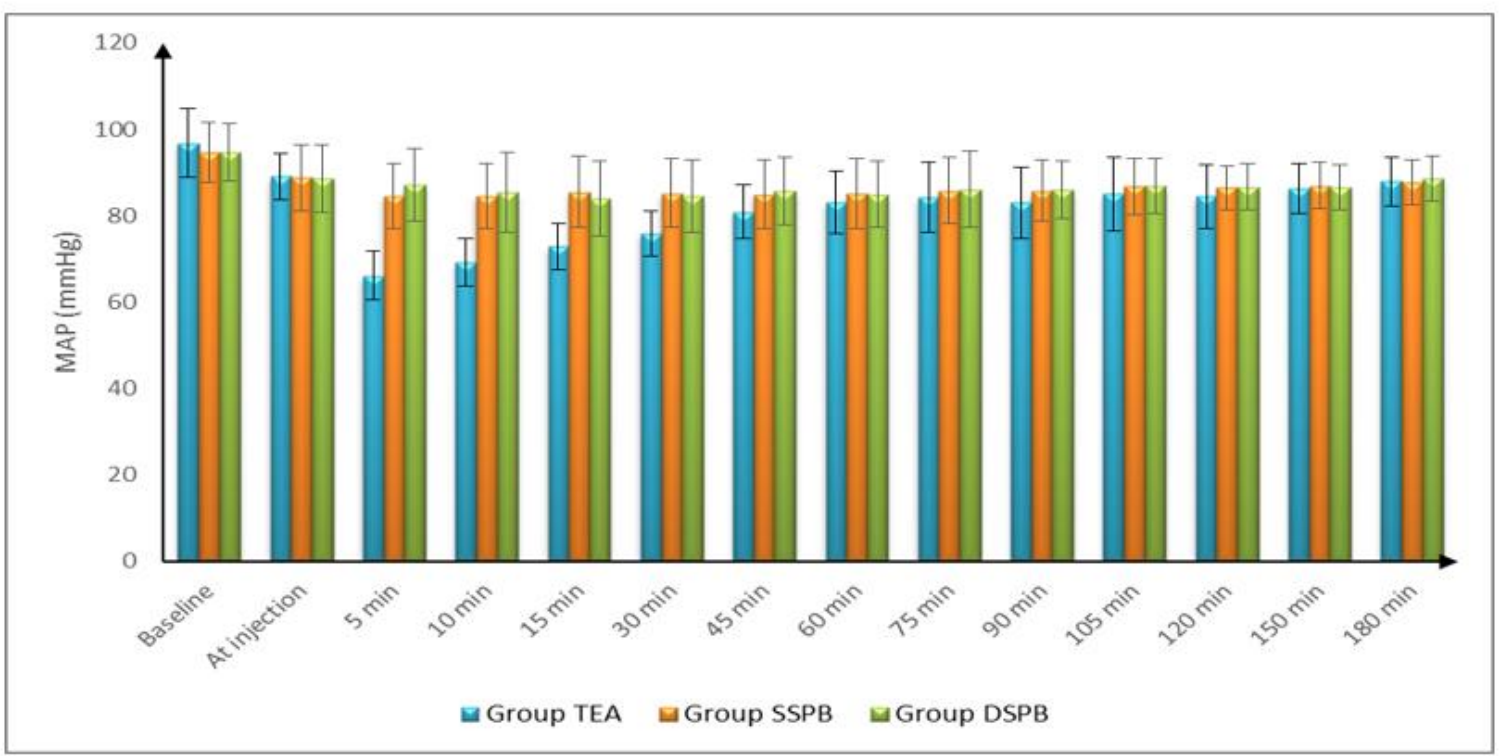

Figure 3: Intraoperative mean blood pressure in the three groups at different times. (Mean \pm SD)

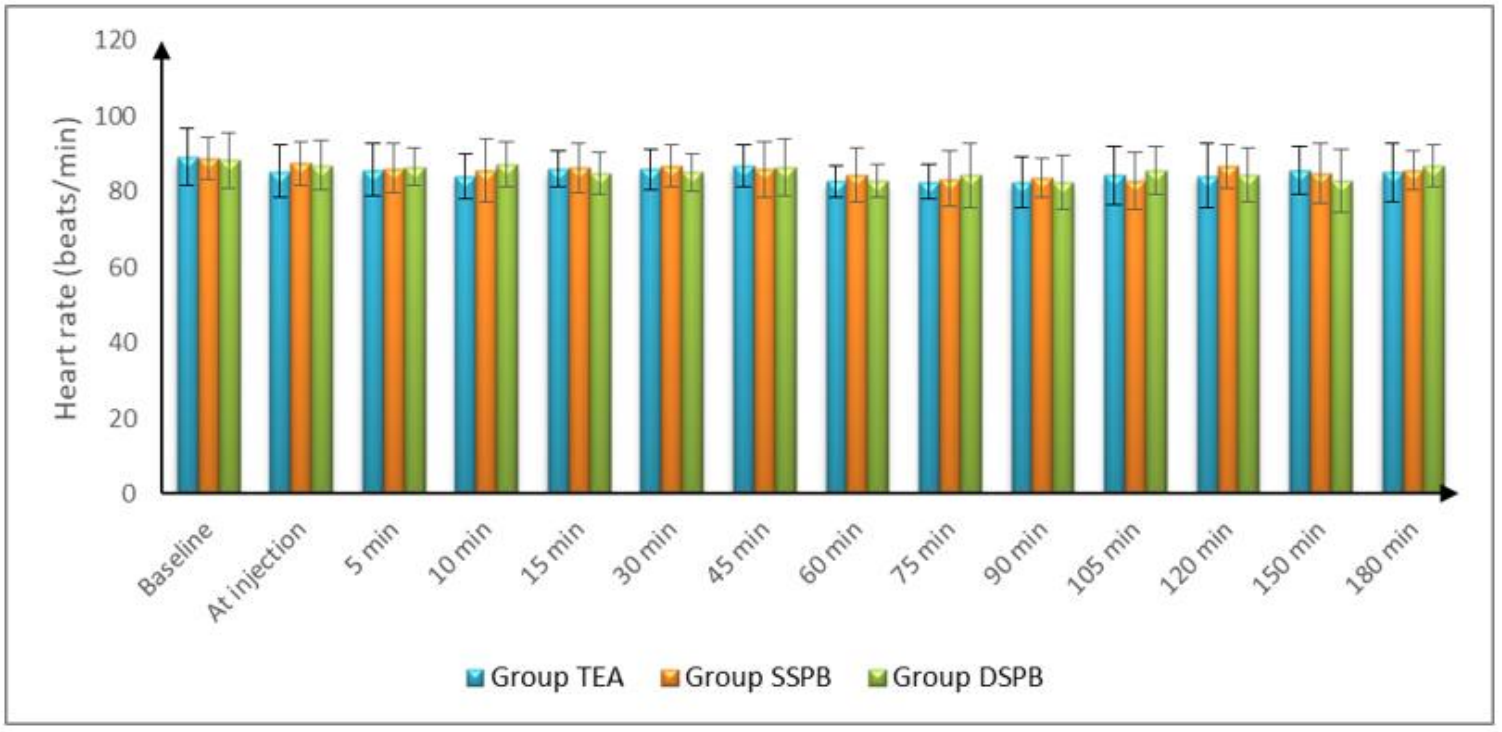

Figure 4: Intraoperative heart rate (beats/min) in the three groups. Data presented as mean \pm SD.

between group TEA and group DSPB, P3: p-value between group SSPB and group DSPB.

TEA Group: thoracic epidural analgesia group, SSPB group: superficial serratus plane block group, DSPB Group: deep serratus plane block group, IQR: inter quartile range. *significant as p-value $<0.05, \mathrm{P} 1$ : $\mathrm{p}-$ value between group TEA and group SSPB, P2: p-value between group TEA and group DSPB, P3: p-value between group SSPB and group DSPB.

The time to $1^{\text {st }}$ morphine request was significantly delayed in SSPB and DSPB groups compared to TEA group with a mean time of $129.32 \pm 32.42 \mathrm{~min}, 126.95 \pm$ $29.55 \mathrm{~min}$ and $61.25 \pm 24.59 \mathrm{~min}$ respectively $(\mathrm{p}<0.001)$ while it was comparable between both SAPB groups $(\mathrm{p}=$ 0.375). The mean total postoperative morphine consumption during the first postoperative day was comparable between TEA (27.03 $\pm 3.36 \mathrm{mg})$, SSPB $(25.88 \pm 3.49 \mathrm{mg})$ and DSPB $(26.19 \pm 3.04)(\mathrm{p}=0.150)$.

\section{Discussion}

This study showed that SSPB and DSPB can provide good peri-operative analgesia without hemodynamic 


\begin{tabular}{|c|c|c|c|c|c|c|}
\hline Variable & & $\begin{array}{l}\text { TEA Group } \\
(\mathrm{n}=59)\end{array}$ & $\begin{array}{l}\text { SSPB Group } \\
(n=57)\end{array}$ & $\begin{array}{l}\text { DSPB Group } \\
(n=59)\end{array}$ & p-value & \\
\hline \multirow[t]{2}{*}{ Age (years) } & Mean \pm SD & $46.41 \pm 8.19$ & $44.19 \pm 9.41$ & $45.47 \pm 9.36$ & 0.415 & - \\
\hline & Range & $26-59$ & $24-60$ & $20-60$ & & - \\
\hline \multirow[t]{2}{*}{ Sex } & Male & $34(57.63 \%)$ & 32 (56.14\%) & 31 (52.54\%) & 0.850 & - \\
\hline & Female & $25(42.37 \%)$ & 25 (43.86\%) & $28(47.46 \%)$ & & - \\
\hline \multirow{3}{*}{$\begin{array}{l}\text { Procedure } \\
\text { time (min) }\end{array}$} & Mean \pm SD & $20.2 \pm 3.32$ & $11.42 \pm 2.57$ & $8.44 \pm 2.20$ & $<0.001^{\star}$ & $P 1:<0.001^{*}$ \\
\hline & Range & $15-25$ & $7-15$ & $5-12$ & & $P 2:<0.001^{*}$ \\
\hline & & & & & & P3: $<0.001^{*}$ \\
\hline \multirow{2}{*}{$\begin{array}{l}\text { Duration of } \\
\text { anesthesia } \\
\text { (min) }\end{array}$} & Mean \pm SD & $213.31 \pm 18.72$ & $209.58 \pm 18.30$ & $210.08 \pm 19.84$ & 0.513 & - \\
\hline & Range & $185-250$ & $180-240$ & $180-260$ & & - \\
\hline \multirow{2}{*}{$\begin{array}{l}\text { Duration of } \\
\text { surgery } \\
\text { (min) }\end{array}$} & Mean \pm SD & $196.10 \pm 19.98$ & $191.78 \pm 19.67$ & $195.93 \pm 18.74$ & 0.396 & - \\
\hline & Range & $160-230$ & $160-225$ & $160-230$ & & - \\
\hline
\end{tabular}

TEA Group: thoracic epidural analgesia group, SSPB group: superficial serratus plane block group, DSPB Group: deep serratus plane block group. SD: Standard deviation, *significant as $p$-value $<0.05, P 1$ : $p$-value between group TEA and group SSPB, P2: $p$-value between group TEA and group DSPB, P3: $p$-value between group $S S P B$ and group DSPB

\begin{tabular}{|c|c|c|c|c|c|c|c|c|c|c|}
\hline \multirow[t]{2}{*}{ Time } & \multicolumn{2}{|c|}{$\begin{array}{l}\text { TEA Group } \\
(n=59)\end{array}$} & \multicolumn{2}{|c|}{$\begin{array}{l}\text { SSPB Group } \\
(\mathrm{n}=57)\end{array}$} & \multicolumn{2}{|c|}{$\begin{array}{l}\text { DSPB Group } \\
(n=59)\end{array}$} & \multirow[t]{2}{*}{ p-value } & \multirow[t]{2}{*}{ P1 } & \multirow[t]{2}{*}{ P2 } & \multirow[t]{2}{*}{ P3 } \\
\hline & Median & IQR & Median & IQR & Median & IQR & & & & \\
\hline $\begin{array}{l}\text { At } \\
\text { admission }\end{array}$ & 1 & $0-2$ & 0 & $0-1$ & 0 & $0-1$ & $0.006^{*}$ & $0.006^{*}$ & $0.007^{\star}$ & 0.959 \\
\hline $1 \mathrm{~h}$ & 3 & $2-4$ & 1 & $0-2$ & 1 & $0-2$ & $<0.001^{*}$ & $<0.001^{*}$ & $<0.001^{*}$ & 0.484 \\
\hline $2 h$ & 3 & $3-4$ & 3 & $3-4$ & 3 & $3-4$ & 0.968 & - & - & - \\
\hline $3 \mathrm{~h}$ & 3 & $3-3$ & 3 & $2-3$ & 3 & $3-3$ & 0.996 & - & - & - \\
\hline $4 \mathrm{~h}$ & 3 & $3-4$ & 3 & $3-4$ & 3 & $3-4$ & 0.832 & - & - & - \\
\hline $5 \mathrm{~h}$ & 3 & $2-3$ & 2 & $2-3$ & 2 & $2-3$ & 0.635 & - & - & - \\
\hline $6 \mathrm{~h}$ & 2 & $1-2$ & 2 & $1-2$ & 2 & $2-2$ & 0.582 & - & - & - \\
\hline $9 \mathrm{~h}$ & 1 & $0-2$ & 1 & $0-2$ & 1 & $0-2$ & 0.838 & - & - & - \\
\hline $12 \mathrm{~h}$ & 0 & $0-1$ & 0 & $0-0$ & 0 & $0-1$ & 0.370 & - & - & - \\
\hline $24 \mathrm{~h}$ & 0 & $0-0$ & 0 & $0-0$ & 0 & $0-0$ & 0.102 & - & - & - \\
\hline
\end{tabular}

instability compared to that provided by TEA in thoracotomies. Hypotension was significantly observed in the TEA group compared to SAPB groups. The total intraoperative fentanyl consumption and the total postoperative morphine consumption were comparable among the three groups. The analgesic duration of the 


\begin{tabular}{|c|c|c|c|c|c|c|c|c|c|c|}
\hline \multirow[t]{2}{*}{ Time } & \multicolumn{2}{|c|}{$\begin{array}{l}\text { TEA Group } \\
(\mathrm{n}=59)\end{array}$} & \multicolumn{2}{|c|}{$\begin{array}{l}\text { SSPB Group } \\
(n=57)\end{array}$} & \multicolumn{2}{|c|}{$\begin{array}{l}\text { DSPB Group } \\
(n=59)\end{array}$} & \multirow[t]{2}{*}{ p-value } & \multirow[t]{2}{*}{ P1 } & \multirow[t]{2}{*}{$\mathbf{P 2}$} & \multirow[t]{2}{*}{ P3 } \\
\hline & Median & IQR & Median & IQR & Median & IQR & & & & \\
\hline $\begin{array}{l}\text { At } \\
\text { admission }\end{array}$ & 3 & $2-4$ & 3 & $2-3$ & 2 & $1-3$ & $0.011^{\star}$ & $0.010^{\star}$ & $0.009^{\star}$ & 0.877 \\
\hline $1 \mathrm{~h}$ & 4 & $4-6$ & 4 & $1-4$ & 3 & $2-4$ & $<0.001^{*}$ & $<0.001^{\star}$ & $<0.001^{\star}$ & 0.509 \\
\hline $2 \mathrm{~h}$ & 5 & $4-6$ & 6 & $5-6$ & 5 & $4-6$ & 0.762 & - & - & - \\
\hline $3 \mathrm{~h}$ & 4 & $4-5$ & 4 & $3-5$ & 5 & $4-5$ & 0.465 & - & - & - \\
\hline $4 \mathrm{~h}$ & 4 & $4-5$ & 5 & $5-5$ & 5 & $4-6$ & 0.336 & - & - & - \\
\hline $5 \mathrm{~h}$ & 4 & $4-5$ & 4 & $4-5$ & 4 & $3-5$ & 0.970 & - & - & - \\
\hline $6 \mathrm{~h}$ & 3 & $3-4$ & 4 & $2-4$ & 3 & $3-4$ & 0.529 & - & - & - \\
\hline $9 \mathrm{~h}$ & 2 & $2-3$ & 2 & $1-3$ & 2 & $2-3$ & 0.933 & - & - & - \\
\hline $12 \mathrm{~h}$ & 2 & $1-3$ & 2 & $2-2$ & 2 & $1-3$ & 0.290 & - & - & - \\
\hline $24 \mathrm{~h}$ & 2 & $1-2$ & 2 & $2-2$ & 1 & $1-2$ & 0.069 & - & - & - \\
\hline
\end{tabular}

single dose of SSPB and DSPB was more prolonged compared to that of single dose of TEA and therefore patients who received TEA showed a higher value of VAS score at ICU admission and in the first postoperative hour at rest and with cough. The rest of the first postoperative day showed comparable VAS scores among the three groups.

The prolonged effect of single dose injection of the local anesthetics in SSPB and DSPB in comparison to single dose injection of the local anesthetics in TEA may be explained by the fact that in the SAPB, the local anesthetics solution is injected into a plane with relatively low vascularity which in turn delays the diffusion of the local anesthetic away from the site of action, so it stays longer exerting its action ${ }^{[6]}$, while in TEA; earlier termination of action may be attributed to the diffusion of the local anesthetics away from the site of action, through the epidural venous plexus. ${ }^{7}$

The current study showed that both SSPB and DSPB were easy techniques that can be performed under U/S guidance with procedural time less than taken to perform thoracic epidural. It was also noticed that the DSPB had less failure rate and shorter procedural time than the SSPB.

Post thoracotomy pain (PTP) has been managed with a multidisciplinary analgesic strategies which combine regional anesthesia with intravenous (IV) drug administration to reduce the side effects of opioids and improve patients' comfort. Multimodal analgesic approaches for thoracotomy pain include IV opioids, non-steroidal anti-inflammatory drugs (NSAIDs) and regional methods such as paravertebral block (PVB) and TEA. ${ }^{8}$

Although the TEA represents the gold standard treatment for thoracotomy pain, many drawbacks has been reported such as urinary retention, neuraxial hematoma and hypotension ${ }^{9]}$ that is explained by the autonomic block caused by the local anesthetic administration.10

In 2013; Blanco and his colleagues introduced SAPB. It provides analgesic effects at approximate levels T2-T9 by blocking the lateral cutaneous branches of the intercostal nerves that traverse through the serratus plane without autonomic block as with TEA and therefore hypotension is not remarkable with SAPB. It is conducted by injecting local anesthetics between serratus anterior muscle and the ribs (deep plane) or between latissimus dorsi and serratus anterior muscles (superficial plane). ${ }^{6}$

SAPB was suggested to be easy and safe procedure because of the superficial position of the target point that doesn't involve any major vessels. ${ }^{6}$ It has been reported to provide efficient analgesia in many different trials such as; in patients with multiple rib fracture compared to TEA and PVB ${ }^{[11]}$, in breast cancer surgeries ${ }^{[12]}$ and minimal invasive heart surgeries ${ }^{13}$

Previous trials were conducted to evaluate the effect of SAPB compared to the TEA in thoracic surgeries. ${ }^{14,15,16}$,

17 This study aimed to evaluate the effect of SSPB, DSPB and TEA in thoracotomies in patients with lung cancer. 
In agreement to the current study, Khalil et al. in 2017 [14] compared postoperative continuous SSPB with continuous TEA, and reported that MAP was significantly lower in the TEA group than in the SSPB group during the whole study period, while HR did not show significant changes over time in both groups. Moreover, total postoperative morphine consumption was comparable between both groups.

However, post-operative VAS pain scores in Khalil et al. study, were comparable in the two groups except in 14, 16 and 22 hours' time points, where pain scores were higher in group SAPB that is in contrast to the current study that showed TEA had higher values of VAS score in the first post- operative hour at rest and with cough while the rest of values were comparable all thorough the remaining 24 hours. This difference may be referred to that in the current study; single dose of the local anesthetics was injected before induction of general anesthesia while Khalil et al used continuous infusion of the local anesthetics in both TEA and SAPB groups.

Moreover, Ökmen et al in 2018; compared DSPB to continuous TEA during the postoperative period of thoracotomy and reported that both groups were comparable regarding the VAS scores and the amounts of post-operative analgesic consumption. ${ }^{15}$

In consistent with the results of the current study, Moon et al. in 2020 compared SSPB with DSPB in thoracoscopic surgeries and reported comparable level of analgesia during the intra-operative period without any significant changes in hemodynamics between both groups. ${ }^{16}$

Recently, Qiu et al. in 2021 divided 66 patients into three groups: group received general anesthesia only, group received combined general anesthesia and SSPB and group received general anesthesia with DSPB and reported that the post- operative VAS score and the total amount of rescue analgesia was significantly lower in groups received SSPB and DSPB than the group received general anesthesia alone with significant higher VAS scores in DSPB group compared to SSPB group at 24 hours' time point $(\mathrm{P}<.001)$, while no significant differences between 6 hours and 12 hours' time points $(\mathrm{P}=.262$ and .178$)$, so SSPB exhibited more stable and longer-lasting analgesic effect than DSPB. ${ }^{17}$

\section{Conclusions}

Pre-operative single injection of SSPB or DSPB can provide good quality of peri-operative analgesia without hemodynamics instability, when compared to single dose injection of TEA. DSPB is easier to be performed with shorter procedural time than SSPB.

\section{Limitations}

This study has some limitations: we used a single shot of TEA and SAPB and we didn't put a catheter to evaluate the analgesic and hemodynamic changes with continuous regional infusions. The follow-up was for 24 hours only.

\section{Conflict of interests}

None declared by the authors. No external funding was involved in the trial.

\section{Authors" contribution}

All authors equally contributed in the preparation of the study protocol, conduct of the study, literature search and manuscript preparation.

\section{References}

1. Gerner P. Postthoracotomy pain management problems. Anesthesiol Clin. 2008;26:355-67. [PubMed] https://doi.org/10.1016/j.anclin.2008.01.007

2. Schwellnus L, Roos R, Naidoo V. Physiotherapy management of patients undergoing thoracotomy procedure: A survey of current practice in Gauteng. S Afr J Physiother. 2017;73:344. [PubMed] https://doi.org/10.4102/sajp.v73i1.344.

3. Okmen K, Okmen BM, Uysal S. Serratus Anterior Plane (SAP) Block Used for Thoracotomy Analgesia: A Case Report. Korean J Pain. 2016;29:189-92. [PubMed] https://doi.org/10.3344/kjp.2016.29.3.189.

4. Joshi GP, Bonnet F, Shah R, Wilkinson RC, Camu F, Fischer $B$, et al. A systematic review of randomized trials evaluating regional techniques for postthoracotomy analgesia. Anesth Analg. 2008;107:1026-40. [PubMed] [Free full text] https://doi.org/10.1213/01.ane.0000333274.63501.ff.

5. Rosero EB, Joshi GP. Nationwide incidence of serious complications of epidural analgesia in the United States. Acta Anaesthesiol Scand. 2016;60:810-20. [PubMed] https://doi.org/10.1111/aas.12702.

6. Blanco R, Parras T, McDonnell JG, Prats-Galino A. Serratus plane block: a novel ultrasound-guided thoracic wall nerve block. Anaesthesia. 2013;68:1107-13. [PubMed] https://doi.org/10.1111/anae.12344.

7. Higuchi $H$, Adachi $Y$, Kazama T. Factors affecting the spread and duration of epidural anesthesia with ropivacaine. Anesthesiology. 2004 Aug;101(2):451-60. [PubMed] https://doi.org/10.1097/00000542-200408000-00027.

8. Kelsheimer B, Williams C, Kelsheimer C. New Emerging Modalities to Treat Post-Thoracotomy Pain Syndrome: A Review. Mo Med. 2019;116:41-4. [PubMed] [Free full text]

9. Gulbahar G, Kocer B, Muratli SN, Yildirim E, Gulbahar O, Dural $\mathrm{K}$, et al. A comparison of epidural and paravertebral catheterisation techniques in post-thoracotomy pain management. Eur J Cardiothorac Surg. 2010;37:467-72. [PubMed] https://doi.org/10.1016/j.ejcts.2009.05.057. 
10. Tighe SQ, Karmakar MK. Serratus plane block: do we need to learn another technique for thoracic wall blockade? Anaesthesia. 2013;68:1103-6. [PubMed] https://doi.org/10.1111/anae.12423.

11. Beard L, Hillermann C, Beard E, Millerchip S, Sachdeva R, Gao Smith $\mathrm{F}$, et al. Multicenter longitudinal cross-sectional study comparing effectiveness of serratus anterior plane, paravertebral and thoracic epidural for the analgesia of multiple rib fractures. Reg Anesth Pain Med. 2020;45:351-6. [PubMed] https://doi.org/10.1136/rapm-2019-101119.

12. Yao Y, Li J, Hu H, Xu T, Chen Y. Ultrasound-guided serratus plane block enhances pain relief and quality of recovery after breast cancer surgery: A randomised controlled trial. Eur J Anaesthesiol. 2019;36:436-41. [PubMed] https://doi.org/10.1097/EJA.0000000000001004.

13. Berthoud V, Ellouze O, Nguyen M, Konstantinou M, Aho S, Malapert G, et al. Serratus anterior plane block for minimal invasive heart surgery. BMC Anesthesiol. 2018;18:144.PubMed] https://doi.org/10.1186/s12871-0180614-5
14. [Khalil AE, Abdallah NM, Bashandy GM, Kaddah TA. Ultrasound-Guided Serratus Anterior Plane Block Versus Thoracic Epidural Analgesia for Thoracotomy Pain. J Cardiothorac Vasc Anesth. 2017;31:152-8. [PubMed] https://doi.org/10.1053/j.jvca.2016.08.023.

15. Ökmen K. Comparison of efficiency of serratus anterior plane block and thoracic epidural block for thoracotomy analgesia. ACEM. 2018;3:156-9. [Free full text] https://doi.org/10.25000/acem.435367.

16. Moon S, Lee J, Kim H, Kim J, Kim J, Kim S. Comparison of the intraoperative analgesic efficacy between ultrasound-guided deep and superficial serratus anterior plane block during videoassisted thoracoscopic lobectomy: A prospective randomized clinical trial. Medicine (Baltimore). 2020;99:e23214. [PubMed] https://doi.org/10.1097/MD.0000000000023214.

17. Qiu L, Bu X, Shen J, Li M, Yang L, Xu Q, et al. Observation of the analgesic effect of superficial or deep anterior serratus plane block on patients undergoing thoracoscopic lobectomy. Medicine (Baltimore). 2021; 100:e24352. [PubMed] https://doi.org/10.1097/MD.0000000000024352. 